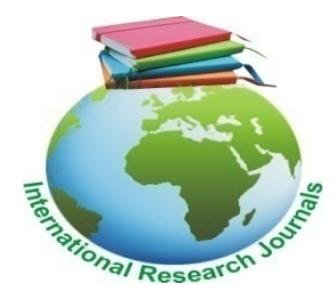

International Research Journal of Microbiology (IRJM) (ISSN: 2141-5463) Vol. 6(3) pp. 037-041, December, 2015

Available online http://www.interesjournals.org/IRJM

DOI: http:/dx.doi.org/10.14303/irjm.2015.140

Copyright (C) 2015 International Research Journals

Full Length Research Paper

\title{
Rats as possible agents of antibiotic resistant Pseudomonas aeruginosa transmission through poultry in Ibadan, Oyo State, Nigeria
}

\author{
${ }^{1}$ Ogunleye Akinlabi Oladele, ${ }^{1}$ Adetosoye Adeyemi Igbekele and Steve Carlson ${ }^{2}$ \\ ${ }^{1}$ Department of Veterinary Microbiology and Parasitology, University of Ibadan Oyo State, Nigeria \\ ${ }^{2}$ Department of Biomedical Sciences, lowa State University of Science and Technology, Ames, USA \\ Corresponding Author's E-mail: peculiarj@yahoo.com, ao.ogunleye@mail.ui.edu.ng. Tel: +234-8054461821.
}

\begin{abstract}
Pseudomonas aeruginosa infections is of public health concerns due to high morbidities and mortalities often occasioned by its multidrug resistant nature, particularly to drugs like fluoroquinolones and cephalosporin. Constant surveillance and tracking of its possible sources of transmission is therefore of epidemiological value. We screened 30 Pseudomonas aeruginosa isolated from oral and rectum swabs of rats captured from some poultry houses in Nigeria; identified by conventional bacteriological procedures and confirmed with 16S ribosomal RNA PCR assay, for their antibiotic susceptibilities to 10 commonly used antibiotics in Nigeria based on standard method. The fluoroquinolone resistant strain were subsequently screened for point mutation at the GyrA of the quinolone resistant determining region(QRDR) through DNA amplification and sequencing. They exhibited $100 \%$ resistance at breakpoint concentrations for; ceftazidime, ceftriaxone, sulfamethoxazole, chloramphenicol, streptomycin and ampicillin. The 4/30(13.33\%) fluoroquinolone resistant isolates displayed a high MICs ranges between $32 \mu \mathrm{g} / \mathrm{mL}$ to $128 \mu \mathrm{g} / \mathrm{mL}$ and one had 1 point mutation. This work shows that rat can be a source of transmission for drug resistant Pseudomonas aeruginosa along the poultry value chain in Nigeria. There is an urgent need for public health education on the health risk associated with the possible transmission of these organism in Nigeria.
\end{abstract}

Keywords: Pseudomonas aeruginosa; rats; poultry; multidrug resistant; Nigeria.

\section{INTRODUCTION}

Pseudomonas aeruginosa is a Gram negative pathogen known as agent of infections that are usually severe and most of the time difficult to treat due to high frequency of antibiotic resistance associated with the pathogen (Carmeli et al., 1999, Garner et al., 1988). They have been incriminated as agents of opportunistic infections, acute pneumonia, chronic lung infection in patients with cystic fibrosis, and is a leading aetiological agent of nosocomial infections (Richards et al., 1999; Agnello and Wong-Beringer, 2012).

Prompt and correct selection of appropriate definitive therapy is critical for the successful treatment of Pseudomonas related infection, because delayed treatment had been associated with mortality ((Kang et al., 2003; Obritsch et al., 2004). All around the world,
Nigeria inclusive, a choice of treatment options for Pseudomonas infection is usually made between three classes of antibiotics, namely: lactams, fluoroquinolones and aminoglycosides (Giamarellou and Antoniadou. 2001). However, of the three groups, fluoroquinolones is often more commonly used (McCaig et al., 2003; Gasink et al., 2006). The choice of appropriate antibiotic therapy for Pseudomonas infection is not always easy because of the high occurrence of multidrug resistance among Pseudomonas aeruginosa isolates (NNIS, 2004;Tacconelli et al., 2002). A multidrug resistant isolate is that which is resistant to 3-4 of the following classes of antibiotics namely: penincillins/ cephalosporins/ monobactams, carbapenems, aminoglycosides and fluoroquinolones (Barber and Wolff, 2010). 
Earlier in Nigeria, 7 high fluoroquinolone resistant Pseudomonas aeruginosa MICs ranges: $8-128 \mu \mathrm{g} / \mathrm{mL}$ for nalidixic acid, 8- 32 $\mu \mathrm{g} / \mathrm{mL}$ for ciprofloxacin, 32- $64 \mu \mathrm{g} / \mathrm{mL}$ for levofloxacin that were also multidrug resistant to various combinations of commonly used antibiotics such as streptomycin,, ampicillin, tetracycline, kanamycin, neomycin and chloramphenicol at breakpoint concentrations were isolated and characterized from poultry that died of septicaemic conditions in Ibadan, Oyo state Nigeria (Ogunleye, 2012). The H150Y substitution was typical of all the Pseudomonas aeruginosa isolates regardless of other resistant pattern observed for each of the other commonly used antibiotics (Ogunleye, 2012). Rats like other rodents have been acknowledged as possible reservoir and agents of transmission of pathogen as well as drug resistant pathogen to animal and human (Meerburg and Kijlstra, 2007). The current work therefore screened 30 Pseudomonas aeruginosa isolated from rats captured in some poultry houses in Ibadan, Oyo State, Nigeria, for their antibiotics susceptibilities to 10 commonly used antibiotics for food animals and humans in the study area. We subsequently screened for point mutation of the quinolone resistant determining region of the fluoroquinolone resistant isolates through PCR assay. The public health implication of the findings in terms of zoonosis and antibiotic resistant transmission was discussed.

\section{MATERIALS AND METHODS}

\section{Bacteria Isolates}

The bacteria isolates studied included 30 Pseudomonas aeruginosa recovered from oral/rectum swabs from rats captured in some commercial poultry houses located in the suburb areas of Ibadan, Oyo State Nigeria. The samples were inoculated onto Pseudomonas agar F (Bio $\mathrm{Lab}$ ) incubated aerobically at $37^{\circ} \mathrm{C}$ for $24-48$ hours. The suspected Pseudomonas species were further characterized morphologically and biochemically based onstandard procedures (Barrow and Felthams, 2004; Garcia and Isenberg, 2007). Their identities were further confirmed with Oxoid Microbact GNB 24E $®$ (MB24E) and accompanying computer software package (Oxoid Microbact $®) 2000$ version 2.03 according to the manufacturers procedures and by16S ribosomal RNA PCR identification procedure.

\section{S RNA Identification of the Pseudomonas aeruginosa}

The $16 \mathrm{~S}$ ribosomal identification of the 30 isolates were based on previously described method (Weisburg et al., 1991) with some modifications. Crude Chromosomal DNA used as templates were produced by heat treatment of the overnight LB culture of the 30 isolates at $99^{\circ} \mathrm{C}$ for 15 minutes. A $100 \mu \mathrm{l}$ of the boiled isolates were mixed with equal volume of PCR grade water, $1 \mu \mathrm{l}$ of the mixture was used as DNA template in a $50 \mu \mathrm{l}$ reaction. The DNA was amplified using QS PCR reagents (New England Bio labs), $1 \mu \mathrm{M}$ of $\mathrm{fD} 2=$ 5'AGATTTGATCATGGCTCAG3' and rP1 = 5'ACGGCTACCTTGTTACGACTT3', including $10 \mu \mathrm{l}$ QS buffer, $1 \mu \mathrm{l}$ dNTPs, $0.25 \mu \mathrm{l}$ fD1, $0.25 \mu \mathrm{l}$ rP1, $0.5 \mu \mathrm{l}$ QS enzyme, $10 \mu \mathrm{l}$ QS enhancer and $27 \mu \mathrm{l} \mathrm{PCR}$ water. The PCR protocol involved: initial denaturation at $98^{\circ} \mathrm{C}$ for 30 seconds, and 35 cycles of DNA denaturation at $98^{\circ} \mathrm{C}$ for 10seconds, primers annealing at $55^{\circ} \mathrm{C}$ for 30 seconds, primers extension at $72^{\circ} \mathrm{C}$ for 1 minute 15 seconds and the final extension at $72^{\circ} \mathrm{C}$ for 7 minutes.

The amplified products were purified with Qiagen kits and sequenced at lowa State University DNA sequencing facilities (Ames, IA, USA). The identities of the sequenced products were analysed by using BLASTN 2.2.31+ as described by Zhang et al., 2000 .

\section{Determination of Resistance to Kanamycin, ampicillin, chloramphenicol, streptomycin, sulfamethoxazole, levofloxacin, ceftazidime, ceftriaxone, cefepime and amikacin}

The isolates were grown aerobically in breakpoint concentrations of $32 \mu \mathrm{g} / \mathrm{mL}$ each for kanamycin, ceftazidime, ceftriaxone, amikacin, ampicillin, and cefepime; at $64 \mu \mathrm{g} / \mathrm{mL}$ for streptomycin, $16 \mu \mathrm{g} / \mathrm{mL}$ for chloramphenicol, sulfamethoxazole at $1024 \mu \mathrm{g} / \mathrm{mL}$ and $8 \mu \mathrm{g} / \mathrm{mL}$ for levofloxacin (all from SIGMA- ALDRICH) according to standard method( CLSI, 2009)

The isolates were considered resistant if flocculent growth was observed after $16 \mathrm{~h}$ of aerobic growth at $37^{\circ} \mathrm{C}$.

\section{Quinolone resistant Determinant Region (QRDR) PCR assay for the Levofloxacin resistant isolates}

Minimum inhibitory concentrations of the $4 / 30$ isolates that were resistant to levofloxacin at $8 \mu \mathrm{l}$ breakpoint were determined by standard method according to the CLSI procedure (CLSI, 2009). The high fluoroquinolone resistant isolates were subsequently screened for point mutation through the amplification of the GyrA QRDR and DNA sequencing of the PCR product. It was carried out as previously described (Ogunleye, 2012).

A 560base pair region of GyrA of the crude boiled DNA was amplified with a universal Forward and reverse oligonucleotide QRDR F=5'ATGAGCGACCTTGCGAGAAATACACCG3' and QRDR R=5'TTCCATCAGCGCCCTTCAATGCTGATGTCTTC3' using QS polymerase reagents (New England Bio labs), in a $50 \mu$ l reaction; containing $10 \mu \mathrm{l}$ QS buffer, $1 \mu \mathrm{l}$ dNTPs, $0.25 \mu \mathrm{l}$ QRDR F, $0.25 \mu \mathrm{l}$ QRDR R, $0.5 \mu \mathrm{l}$ QS enzyme, $10 \mu \mathrm{l}$ QS enhancer 
Table 1: Antibiotic resistance patterns of Pseudomonas aeruginosa isolated from rat in poultry house from Nigeria.

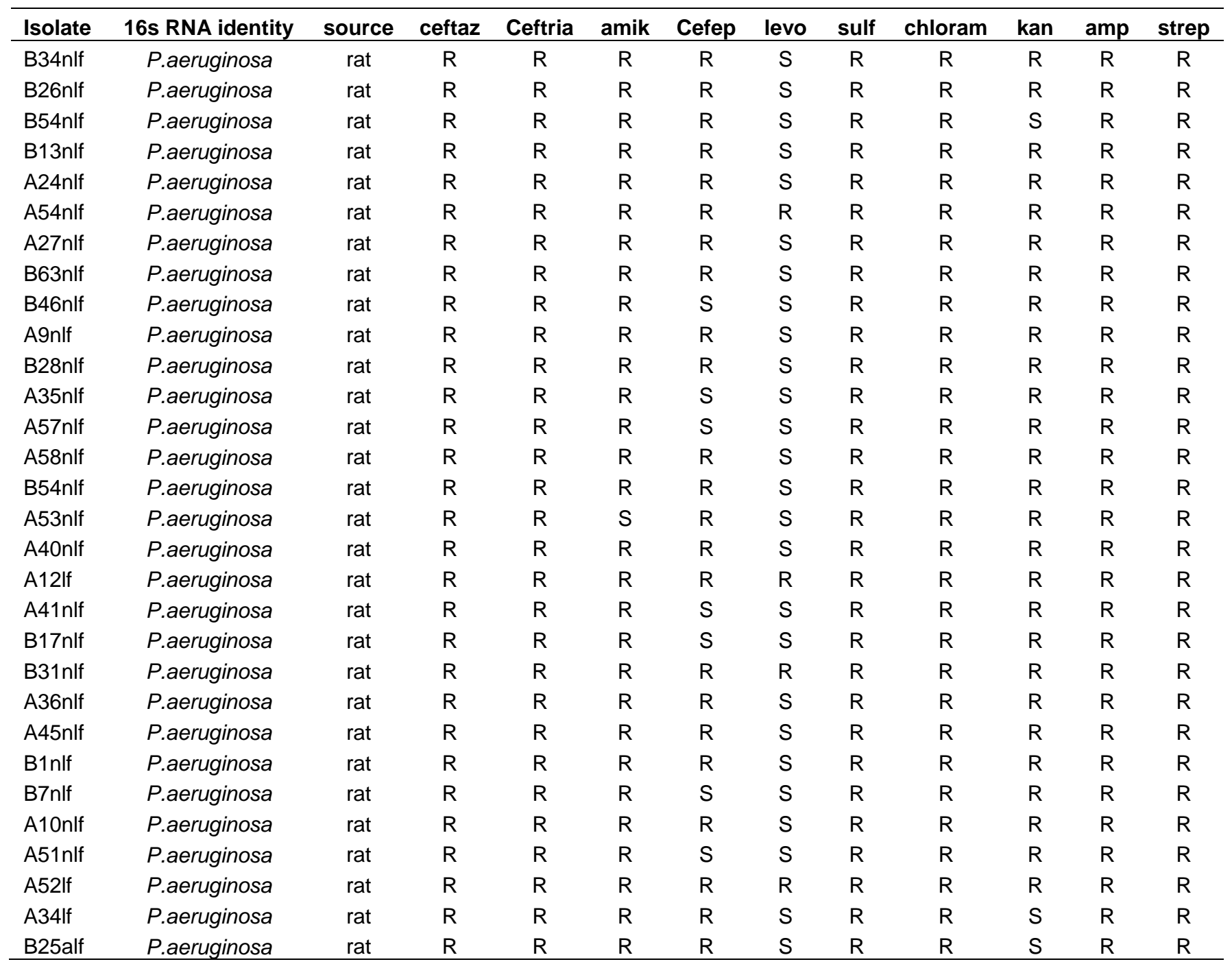

$P$. aeruginosa= Pseudomonas aeruginosa; Ceftaz=ceftazidime; ceftria= ceftriaxone; amik= amikacin; cefep= cefepime; levo=levofloxacin; sulf= sulfamethoxazole, kan= kanamycin; amp= ampicillin; strep= streptomycin; R= resistant; $\mathrm{S}=$ sensitive

and $27 \mu \mathrm{l} \mathrm{PCR}$ water, using the PCR protocol: initial denaturation of $98^{\circ} \mathrm{C}$ for 30 seconds, and 35 cycles of DNA denaturation at $98^{\circ} \mathrm{C}$ for 10 seconds,primers annealing at $55^{\circ} \mathrm{C}$ for 30 seconds, primer extension at $72^{\circ} \mathrm{C}$ for 1 minute 15 seconds and a final extension at $72^{\circ} \mathrm{C}$ for 7 minutes. The amplified products were resolved with precast E- gel in an Electrophoresis unit (Life Technologies). The amplified products were purified with Qiagen kits and sequenced at lowa State University DNA sequencing facilities (Ames, IA, USA)

\section{RESULTS}

The 30 isolates were identified as Pseudomonas aeruginosa based on standard bacteriological procedures and further confirmed with (Oxoid Microbact $\AA$ ) 2000 version 2.03 according to the manufacturers procedures and through $16 \mathrm{~S}$ ribosomal RNA PCR identification procedure.

All the 30 isolates were multidrug resistant; all the isolates had $100 \%(30 / 30)$ resistance to six of the antibiotics including: ceftazidime, ceftriaxone, sulfamethoxazole, chloramphenicol, streptomycin and ampicillin, followed by $96.66 \%(29 / 30)$ for amikacin, $90 \%(27 / 30)$ for kanamycin, $76.66 \%(23 / 30)$ for cefepime and $13.33 \%(4 / 30)$ for levofloxacin (Table 1).

As reflected in Table 2, levofloxacin resistant isolates exhibited high minimum inhibitory concentrations values ranging from $32 \mu \mathrm{g} / \mathrm{mL}$ to $128 \mu \mathrm{g} / \mathrm{mL}$ for levofloxacin. One 
40 Int. Res. J. Microbiol.

Table 2: Levofloxacin Minimum inhibitory concentrations and point mutation in quinolone resistant $P$ seudomonas aeruginosaisolated from rat in poultry house from Nigeria

\begin{tabular}{lcccc}
\hline Isolate & 16s RNA identity & No of point mutation & Levo $(8 \mu \mathrm{g} / \mathrm{mL}$ & Levo $\mathbf{M I C}$ \\
\hline A12nlf & $P$ aerug & Nil & $\mathrm{R}$ & $128 \mu \mathrm{g} / \mathrm{mL}$ \\
A54nlf & $P$ aerug & 1 & $\mathrm{R}$ & $32 \mu \mathrm{g} / \mathrm{mL}$ \\
A52lf & $P$ aerug & Nil & $\mathrm{R}$ & $128 \mu \mathrm{g} / \mathrm{mL}$ \\
B31nlf & $P$ aerug & Nil & $\mathrm{R}$ & $128 \mu \mathrm{g} / \mathrm{mL}$ \\
\hline
\end{tabular}

$P$ aerug $=$ Pseudomonas aeruginosa; 16s RNA id= 16s Ribosomal RNA identification; levo= Levofloxacin, levo $\mathrm{MIC}=$ levofloxacin minimum inhibitory concentration; $\mathrm{R}=$ resistant.

isolate A54nlf with MIC value $32 \mu \mathrm{g} / \mathrm{mL}$ had 1 point mutation.

\section{DISCUSSION}

Pseudomonas aeruginosa; one important opportunistic Gram negative infectious agent requires prompt and appropriate antibiotic treatment, otherwise could often lead to a higher tendencies for mortalities in infected individuals( Kang et al., 2003;Micek et al., 2005).

Of all the infections by Gram negative bacteria, it has been noted for its high morbidity and mortalities particularly among critically ill and immune-compromised patients (Marshal et al., 1993; Andremont et al., 1989; Dantas and Moretti-Branchini, 2003; Aliaga et al., 2002). The mortalities is usually caused by increased in the rate of drug resistance especially to drug of choice for its treatment, like fluoroquilonones (Gasnik et al., 2006). Information on the drug resistance status of the organism and tracking of the possible sources of drug resistant Pseudomonas aeruginosa to the public is therefore imperative.

In the current work, all the 30 Pseudomonas aeruginosa isolated from rats within the poultry houses screened show that rat could constitute a serious public health problem to poultry production and human health based on the antibiotic resistance status of the pathogens. All the isolates were multidrug resistant including resistance to cephalosporin, aminoglycosides as well as to fluoroquinolone drug tested. Similar strains of Pseudomonas aeruginosa had earlier been isolated and characterized from poultry in the studied area in Nigeria (Ogunleye, 2012). From the findings of this work, rats thus rank very high as the possible source of the drug resistant Pseudomonas aeruginosa in poultry in Ibadan, Oyo State, Nigeria.

Going by the antibiotic resistance status exhibited by the pathogen screened from this study, there is a great threat to public health should the organisms be transmitted through food chain to human, or should they transmit the resistance factors to other food animal pathogen or human pathogen from the poultry handlers or through the poultry production value chain. Infection with pathogen with this kind of antibiotic resistance status could lead to a high morbidity and mortalities as earlier noted (Gasnik et al., 2006). The current findings calls for prompt public health awareness on the risk factors associated with rats as agent of zoonotic pathogen transmission as well as drug resistant pathogen transmission to food animal and human. There is a need for a nationwide surveillance study targeted at screening rats for potential pathogens and drug resistant pathogen, so as to put a scientifically informed necessary preventive measures and policies in place to avert possible public health disaster that may results from unsuspecting spread of such organisms to the public.

\section{ACKNOWLEDGEMENT}

This work was funded by the grant provided by the Nigeria University Revitalization fund, 2015 awarded by the University of Ibadan for a short Veterinary diagnostic Training and Research at the College of Veterinary Medicine, lowa State University of Science and Technology, Ames, lowa State, USA

\section{REFERENCES}

Agnello M, Wong-Beringer A (2012). Differentiation in Quinolone Resistance by Virulence Genotype in Pseudomonas aeruginosa. PLoS ONE. 7(8): e42973.

Aliaga L, Mediavilla JD, Cobo F (2002). A clinical index predicting mortality with Pseudomonas aeruginosa bacteraemia. J Med Microbiol. 51:615-619.

Andremont A, Marang B, Tancrede C, Baume D, Hill C (1989). Antibiotic treatment and intestinal colonization by Pseudomonas aeruginosa in cancer patients. Antimicrob Agents Chemother. 33:1400-1402.

Barber F, Wolff M (2010). Multi-drug resistant Pseudomonas aeruginosa: towards a therapeutic dead end? 2010. MEDECINE/SCIENCES. 26: 960-968.

Barrow GI, Felthan RKA (2004). Cowan and Steels identification of Medical bacteria 4th edition Cambridge University Press, 50-145.

Carmeli Y, Troillet N, Eliopoulos G, Samore MH (1999). Emergence of antibiotic-resistant Pseudomonas aeruginosa: comparison of risks associated with different anti pseudomonal agents. Antimicrob. Agents Chemother. 43:1379-1382. 
CLSI (2009). Method of dilution antimicrobial susceptibility test for bacteria that grow aerobically: ApprovedStandard- 8thEdn. CLSI document M31-A3, 1-99. Clinical and Laboratory Standards Institute, 940 West Valley Road, Wayne, Pennsylvania, USA.

Dantas SR, Moretti-Branchini ML (2003). Impact of antibiotic-resistant pathogens colonizing the respiratory secretions of patients in an extended-care area of the emergency department. Infect Control Hosp Epidemiol. 24:351-355.

Garcia LS, Isenberg HD (2007). Clinical Microbiology Procedures Handbook Vol. 1, Second edn. Update ASM Press American Society for Microbiology 1752 N St., N.W. Washington, DC 20036290.

Garner JS, Jarvis WR, Emori TG, Horan TC, Hughes JM (1988). CDC definitions for nosocomial infections. Am. J. Infect. Control. 16:128-140.

Gasink LB, Fishman NO, Weiner MG, Nachamkin I, Bilker WB, Lautenbach E (2006). Fluoroquinolone-Resistant Pseudomonas aeruginosa: Assessment of Risk Factors and Clinical Impact. The American Journal of Medicine.19: 526.e19-526.e25.

Giamarellou H, Antoniadou A (2001). Antipseudomonal antibiotics. Medical Clinics of North America. 85: $19-41$.

Kang Cl, Kim SH, Kim HB, Park SW, Choe YJ, Oh MD, Kim EC, Choe KW. (2003). Pseudomonas aeruginosa bacteremia: risk factors for mortality and influence of delayed receipt of effective antimicrobial therapy on clinical outcome. Clin Infect Dis.2003; 37:745-751.

Marshall JC, Christou NV, Meakins JL (1993). The gastrointestinal tract. The "undrained abscess" of multiple organ failure. Ann Surg. 218:111-119.

McCaig LF, Besser RE, Hughes JM (2003). Antimicrobial drug prescriptions in ambulatory care settings, United States, $1992-$ 2000. Emerging Infect. Dis. 9: 432 - 437.

Meerburg BG, Kijlstra A(2007). Role of rodents in transmission of Salmonella and Campylobacter. J Sci Food Agric. 87:2774 - 2781.
Micek ST, Lloyd AE, Ritchie DJ, Reichley RM, Fraser VJ, Kollef $\mathrm{MH}$ (2005). Pseudomonas aeruginosa bloodstream infection: importance of appropriate initial antimicrobial treatment. Antimicrob Agents Chemother. 49:1306-1311.

NNIS (2004).National Nosocomial Infection Surveillance System. National Nosocomial Infection Surveillance (NNIS) System report, data summary from January 1992 through June 2004, issued October 2004. Am. J. Infect. Control. 32:470-485.

Obritsch MD, Fish DN, MacLaren R, Jung R (2004). National surveillance of antimicrobial resistance in Pseudomonas aeruginosa isolates obtained from intensive care unit patients from 1993 to 2002. Antimicrob Agents Chemother. 2004; 48:4606-4610.

Ogunleye AO (2012): Identification of GyrA mutations conferring fluoroquinolone resistance in Pseudomonas aeruginosa isolated from septic poultry in Ibadan, Oyo State Nigeria.Afr. J. Microbiol. Res. 6(6): 1249-1254.

Richards MJ, Edwards JR, Culver DH, Gaynes RP (1999). Nosocomial infections in medical intensive care units in the United States. National Nosocomial Infections Surveillance System. Crit Care Med 1999; 27:887-92.

Tacconelli E, Tumbarello M,bertagnolio S, Citton R, Spanu T, Fadda G, Cauda R(2002). Multidrug resistant Pseudomonas aeruginosa blood stream infection: Analysis of trends in prevalence and Epidemiology. Emerg infect Dis. 8(2): 220-221.

Weisburg WG, Barns SM, Pelletier DA, Lane DJ (1991). 16S Ribosomal DNA Amplification for Phylogenetic Study. Journal of Bacteriology. 173(2): 697-7030021-9193/91/020697-07\$02.00/0.

Zhang Z, Schwartz S, Wagner, Miller W (2000). A greedy alogarithm for aligning DNA sequences.2000. J comput Biol. 7(1-2): 203-214. 